\title{
IT Education for Hospitality Managers
}

\author{
Barbara Tatnall \\ School of Tourism and Hospitality \\ Northern Melbourne Institute of TAFE \\ Melbourne, Australia
}

\begin{abstract}
What level of understanding do Hospitality Management students require of Information Technology in order to fulfil their future roles in industry? This paper describes computing courses offered in Hospitality Management in the Australian TAFE sector and how these courses are attempting to meet the needs of the industry. There has recently been a significant shift in the way that hospitality establishments obtain information systems, away from the building of customised systems towards specialised packaged systems. New curriculum developments are reflecting these changes in the industry.
\end{abstract}

\section{Keywords}

Hospitality management, management education, information technology, technical and further education.

\section{INTRODUCTION}

In Australia, Institutes of Technical and Further Education (TAFE) fill a role similar to that of the Polytechnic of many other countries, and a little different to that of the universities. Currently Institutes of TAFE do not award degrees, but offer vocational courses ranging from one to three years in duration. Hospitality students typically begin their TAFE courses after completing year 12 at a secondary school, and hence are around eighteen years of age.

1996 has seen the commencement of the phased adoption of a new National Curriculum in Hospitality which will be fully in place by 1998 , so at the present time the course is in transition. The old course has been of a three-tiered structure with the emphasis in the first year - the Advanced Certificate year, on operational skills. The second year - the Associate Diploma year, concentrates on supervisory skills. Those students who continue to the third year undertake a Diploma of Business in Hospitality Management and, in the subject Management and Computers, study the use of IT in business management. Only about $20 \%$ of students, however, stay to complete the third year. 


\section{THE 'MANAGEMENT AND COMPUTERS' SUBJECT}

In the current Diploma course, the subject Management and Computers aims to 'provide students the knowledge and skills to identify, enunciate, develop and implement an information system in a hospitality business' (TAFE, 1994), a tall order indeed in a thirty-four hour subject for students with very little background in computing or management!

The course covers the following topics: information systems, development of computerbased information systems, computers in office automation and operations, information resource management concepts and management information services, computers and strategic planning of corporate policy and direction.

More specifically, the learning outcomes and performance criteria for these topics are as follows. For each of these topics, students must demonstrate a competency of understanding which may be demonstrated through class participation, written or verbal tests, in-class computer exercises or written investigations.

- Detail the role of information systems in business operations and management - basic components of a business system, information requirements of management, functions of management, management roles, levels of management, information quality, internal vs external information, transaction processing systems, management reporting systems, decision support systems, expert systems, executive information systems.

- Describe the process by which computer-based information systems are developed - the systems approach, systems development cycle, computer-assisted systems development (CASE tools), systems analysis and design, involvement of users in analysis and design, feasibility studies, cost-benefit analyses, requirements definition, applicability of batch and on-line systems to specific hospitality applications.

- Describe the role played by computers in office automation and operations - functions of office automation, the role of word processing; electronic mail and other types of electronic communications, IT support for marketing; production; operations and personnel functions, accounting and financial control.

- Analyse information resource management concepts and management information services identifying the challenges that computer-based information systems present to business managers - challenges to management techniques posed by the increased processing capacity of computers, distributed networks and client-server architecture supporting either centralised or decentralised systems and chain operations, information resource management, management involvement in planning and control, user resistance to the introduction of computers, career areas in IT, project management.

- Describe major impacts that computer-based information systems present to the strategic planning of corporate policy and direction - strategic planning and its application to IT, strategic planning approaches specific to the hospitality industry, advantages of strategic planning, benefits to customers from the integration of IT planning in the strategic planning process.

This list of topics has much in common with many IT courses studied by students intending to make a career in computing. One could question the appropriateness of such a curriculum to students whose primary interest is in hotel management. How much do these students need to know about the development of IT systems? Quite clearly these TAFE students have no 
interest in becoming systems analysts or systems developers, and even if they did, it would be impossible to go into sufficient depth to achieve this in the available time. How then should a course like this be tackled?

Managers in hospitality, as in all areas, need to understand something of the basis of information technology so that they can be fully involved in the appropriate implementation and use of the systems that have become essential to effective hotel operations. No large hotel would now be able to operate without IT and most small hotels, restaurants and conference venues make extensive use of computer-based information systems. Hospitality managers are unlikely to have any significant technical role in the development of new information systems, but it is most important that they have an understanding of what is involved in these developments. They must also know what an information system can do and what it cannot. As they will need to make use of information systems in their daily work they need to know the full extent of reporting and decision support capabilities available.

In delivering this course, the emphasis that I place is on an understanding of the potential of information systems to management in the workplace, rather than a technical knowledge of computers. In database management, for instance, after very briefly considering the concept of a relational database, I introduce students to some practical database applications in hospitality. The course content includes a discussion of CASE tools and, as it is impractical from both a cost and time point of view to use some of the commercial products available, I put the students through a simple class exercise using the dBASE IV applications generator to build a small system (Tatnall and Davey, 1995). I then show the students a demonstration of an expert system which selects wines appropriate to serve with particular dishes. This gives students a practical understanding of the questioning approach of an expert system, while not burdening them with the time and effort required to construct a system like this.

The use of computer software for project management is an important concept, but one that is not easy to teach to students with no practical management experience, particularly in the time available for this topic. Over two weeks my students work through setting up the plan for a cake shop to extend its premises and expand its business, using Microsoft Project (Tatnall and Davey, 1995).

\section{A PARADIGM SHIFT IN HOSPITALITY IT USE}

Whilst it may have been true that large hotel chains in the past often developed their own inhouse information systems which would have made a detailed understanding by managers of systems development desirable, this is no longer the case. The Hospitality industry now looks to the use of integrated, commercially available information systems, to fully control hotel operations. Such systems as Fidelio, Hoteliers Information System (HIS) and Hospitality and Leisure System (HAL) are now meeting the needs of most hospitality outlets, making the development of custom systems neither necessary, nor cost efficient. A system like Fidelio has modules covering all aspects of a hospitality operation including a food and beverage module, front office, back office and sales and catering modules.

The larger hotels would previously have employed their own IT professionals to develop and maintain their own in-house systems, and although some still do, this is now the exception. Hotel management is now in the position of needing to choose between the several hotel 
management packages that are available. To assist them in this choice it is desirable that they have some training in determining how a particular software package relates to their specific requirements, and the factors by which you can judge one package to be superior to another. Hotels using one of the commercial packages pay an annual software maintenance fee which includes on-line support from the supplier. They may employ someone to look after the systems in-house, but this person would often have little or no IT training, and problems would be referred back to the supplier.

Hospitality managers of the larger establishments today thus require less detailed knowledge of how systems are developed, but have even more need to understand the capabilities of the information systems that they employ. Some understanding of how to judge software quality would also be useful.

However, not all hospitality establishments are large ones. The cost of purchasing one of the major software packages is not a problem for the larger hotels and convention centres, but for smaller establishments these packages can be beyond reach. For these smaller organisations other custom packages are available, but another alternative is for them to just use a system built in Lotus or Excel, or a database package like dBASE or Access, and adapt this to suit their requirements. In this case, some understanding of spreadsheet and database concepts would be desirable, at least to the level where they may recognise a need to bring in an 'expert' to set the system up for them and customise it their requirements.

\section{COMPUTING IN THE NEW NATIONAL HOSPITALITY MANAGEMENT CURRICULUM}

In 1998 Northern Melbourne Institute of TAFE will introduce the new core management level module 'Computing' as a subject in the Advanced Diploma in Hospitality (ACTRAC, 1995). This newly developed subject recognises the importance of IT for managers by increasing the student contact hours from thirty-four to fifty-four. It has far less emphasis on systems development, reflecting the shift that has taken place in the industry.

Its content includes the following: computer systems and their application, purchasing and upgrading computer hardware and software, the impact of computer systems, data presentation, computer systems maintenance and security. The course consists of six learning outcomes, each of which has a number of assessment criteria.

1. Make recommendations for the acquisition or upgrade of a computer system for a business unit - information requirements for a hospitality business, number of users in the business unit, limitations of the existing information system, strengths and weaknesses of improving or replacing an existing system.

2. Investigation of the main types of hardware components currently available to the Australian market, and determination of their uses and applicability to the Hospitality industry - hardware components, range and use of these components, applicability of components with respect to the needs of various types of establishments.

3. Identification and evaluation of software packages used in the Hospitality industry - types available for various establishments, sources of software, requirements of various software applications, strengths and weaknesses of particular software applications, feasibility of upgrading existing software. 
4. Assessment of the impact of introducing a computer system - advantages and disadvantages of computerisation for hotel guests, advantages and disadvantages of computerisation for the business, identification of training needs for existing and new staff, costs of training.

5. Operation of an information system - data input elements for various hospitality operations, analysis of the output from various hospitality applications, methods of presenting information for decision making purposes, information requirements of management, issues in reporting.

6. Carrying out basic security and maintenance functions for a hospitality computer system computer security needs in the hospitality industry, maintaining security, components and considerations of back-up procedures, issues in system maintenance, identification and resolution of equipment problems, sources of help with equipment problems.

Although it is difficult to comment on this course before attempting to implement it, the course appears to focus more on the current use of IT in the Hospitality Industry and the skills that would be necessary for Hospitality Managers. There is an emphasis on the acquisition and management of the information system and on its operations, rather than on systems development as in the previous course. This reflects the fact that hospitality managers are now responsive to and directly responsible for the management of the information resource in their area of the business, whereas in the past they may have had the assistance of an IT professional in this.

There do appear, however, to be some shortcomings. The commercial hospitality packages are all, in essence, specialised database management systems, but neither this new management level subject, nor other computing modules that are delivered at lower course levels, give any consideration to a basic understanding of database and data modelling concepts. In a number of other subjects students have the opportunity to use commercial systems, such as those mentioned, on an operational level. Nowhere, however, will they be asked to look below the surface to find out how these systems work. Clearly, a detailed knowledge of E-R diagrams and normalisation is beyond their needs, but students should have some understanding of what constitutes a database system and why these systems operate as they do, if for no other reason than this will assist in systems maintenance.

Then again, there are the smaller establishments. Managers involved in this part of the Hospitality Industry are even less likely to have IT support, and often need to work out their information management problems alone. A course in IT for Hospitality Managers should also give more attention to the needs of these people.

\section{CONCLUSION}

The increased sophistication of hospitality information systems has enabled managers to obtain better access to information which they can then use to assist in day-to-day management and in strategic planning. These systems are far easier to use, requiring less technical expertise from the users. Changes in TAFE curricula for the education of Hospitality Management students in Australia, whilst not covering all aspects of information technology for management, have attempted to reflect changes in the way information systems are used in the Hospitality Industry. 


\section{REFERENCES}

TAFE, (1994); Diploma of Business in Hospitality Management, Management and Computers: course outline.

Tatnall, Arthur and Davey, Bill (1995); Management Information Systems for the Hospitality Industry ( $2^{\text {nd }}$ edition), Data Publishing, Melbourne.

ACTRAC, (1995); Computing: Core Management Level Module MC9.

\section{BIOGRAPHY}

Barbara Tatnall is a Program Co-ordinator in the School of Tourism and Hospitality at Northern Melbourne Institute of Technical and Further Education. She teaches computing, including a unit in third year level to management students. 